\title{
Development of a novel vaccine delivery system based on Gantrez nanoparticles
}

Sara Gómez ${ }^{1}$, Carlos Gamazo ${ }^{1}$, Beatriz San Roman ${ }^{1}$, Christine Vauthier ${ }^{2}$, Marta Ferrer ${ }^{3}$, Juan M. Irache ${ }^{1 *}$

1 Adjuvant Unit, Department of Pharmaceutical Technology and Microbiology, University of Navarra, 31080 Pamplona, Spain.

${ }^{2}$ Laboratoire de Physico-chimie, Pharmacotechnie et Biopharmacie UMR CNRS 8612, Faculté de Pharmacie, Université Paris-Sud, 5 av. J.-B. Clément, 92296 ChâtenayMalabry, France.

${ }^{3}$ Allergy Department, Clínica Universitaria, 31080 Pamplona, Spain.

\section{*Corresponding autor:}

Dr. Juan M. Irache

Centro Galénico. University of Navarra

Ap.177, 31080 Pamplona. Spain

Tel: +34 948 425600; Fax: +34 948425649

e-mail: jmirache@unav.es 


\section{Abstract}

The adjuvant capacity of a novel vaccine vector "Gantrez-nanoparticles" (NP) towards coated or encapsulated ovalbumin (OVA) was investigated. OVA nanoparticles were prepared by a solvent displacement method previously described. The protein was incorporated during the manufacturing process (OVA-encapsulated nanoparticles) or after the preparation (OVA-coated nanoparticles). The mean size of the different nanoparticle formulations was lower than $300 \mathrm{~nm}$, and the OVA content ranged approximately from $67 \mu \mathrm{g} / \mathrm{mg}$ nanoparticles (for OVA-coated nanoparticles) to 30 $\mu \mathrm{g} / \mathrm{mg}$ nanoparticles (for OVA-encapsulated nanoparticles). All the OVA-NP formulations were capable of amplifying the antibodies titres (IgG1 and IgG2a) in mice after a single subcutaneous inoculation with respect free OVA or OVA adsorbed to Alum. Furthermore, the elicited response was, for some formulations, predominantly Th1 subtype. Thus, the formulation that contained mainly the antigen inside, and with a low concentration of cross-linking agent, displayed the best potential to induce a Th1 response after 35 days post-immunisation. These results are highly suggestive for the use of Gantrez nanoparticles as an efficient antigen delivery system, especially when a long lasting Th1 cytokine response is required.

Keywords: Gantrez, nanoparticles, adjuvant, vacine-carrier 


\section{Introduction}

The optimization of the efficacy of vaccines relies on the development of effective adjuvants including the antigen delivery systems. Alum (aluminium hydroxide) and MF59 (an oil-in-water emulsion containing metabolizable oil squalene and the surfactants Tween 80 and sorbitan trioleate Span 85) are currently the only adjuvants that have been approved in most countries for vaccine administration in humans ${ }^{1}$. Unfortunately, they produce sometimes adverse reactions, they are poor inducers of cell mediated immunity, and multiple injections are generally necessary to maintain an adequate level and duration of immunity ${ }^{2}$. The single dose administration is an important pilar of the "gold standard" for vaccination, and controlled release of encapsulated antigens from biodegradable polymeric vectors (micro or nanoparticles) or other types of formulations such as liposomes ${ }^{3}$, virosomes ${ }^{4-6}$, ISCOMs (immunostimulatory complexes) ${ }^{7}$ or virus-like particles ${ }^{8,9}$ may have here a key role. In this context, formulations based on PLGA copolymers, which include poly(lactide) homopolymer (PLA) and poly(lactide co-glycolide) copolymer (PLGA), have been approved for human use ${ }^{10}$. This kind of particulate vaccine delivery systems has a lot of advantages such as: i) the protection of the encapsulated active product against its enzymatic inactivation, ii) the increase of the stability of the material incorporated during the manufacturing process, transport and storage of such active product, iii) the improvement of the efficacy of the presentation to the antigen presenting cells (APC), and iv) the increase of the half life of the active product in the organism ${ }^{11-13}$.

One of the main criteria in the choice of a vaccine depends on the sort of the immune response elicited. The vaccine should be able to induce an immune response resulting in protection, and here, the sort of the immune response is very relevant. 
Generally, the type (Th1 or Th2) and duration of the immune response mainly depends on physicochemical properties of the adjuvant vector such as size, polymeric nature, release profile (stability of the vectors) and antigen location on the particle ${ }^{14}$. The summation of these physicochemical properties deeply affects the magnitude and the pathway of antigen presentations. Another important factor that can affect the antigen presentation is the complement activation and coating of the antigen loaded carriers. This property is also extremely related to the surface of the carriers ${ }^{15}$.

Therefore, we describe here, for the first time, the adjuvant capacity of Gantrez nanoparticles using OVA as antigen model. The effect of OVA location (coating the surface or encapsulated into the matrix) as well as the effect of cross-linkage of nanoparticles on the antibody immune response was also studied. Gantrez AN is a copolymer of methyl vinyl ether and maleic anhydride which can easily react with amino groups. In this context, previous studies have demonstrated its efficacy to load or link different types of proteins, such as bovine serum albumin (BSA) ${ }^{16}$ and flagellin ${ }^{17}$.

\section{Material and methods}

\subsection{Chemicals}

Gantrez $^{\circledR}$ AN 119 [poly(methyl vinyl ether-co-maleic anhydride); MW 200,000] was kindly gifted by ISP (Barcelona, Spain). Ovalbumin (OVA) (grade V), 1.3diaminopropane (DP), 2,2-Azino-bis(3-ethylbenzo-thiazoline-6-sulfonic acid) diammonium salt (ABTS), alhidrogel and the anti C3 and C3b goat antiserum, were purchased from Sigma-Aldrich Chemie (Germany). The MicroBCA protein assay was

supplied by Pierce (USA). The peroxidase immunoconjugates $\left(\mathrm{GAM} / \mathrm{IgG}_{1} / \mathrm{PO}\right.$ and 
$\mathrm{GAM} / \mathrm{IgG}_{2 \mathrm{a}} / \mathrm{PO}$ ) were obtained from Nordic Immunology (The Netherlands). All other chemicals used were of reagent grade and obtained from Merck (Spain).

\subsection{Preparation of Gantrez nanoparticles}

Gantrez nanoparticles were prepared by a solvent displacement method previously described ${ }^{16}$. The model protein was incorporated during the manufacture process (OVA-loaded nanoparticles) or after the preparation of the adjuvant vectors (OVA-coated nanoparticles).

\subsubsection{Preparation of OVA-coated Gantrez, nanoparticles (NP I)}

Gantrez copolymer $100 \mathrm{mg}$ was dissolved in $5 \mathrm{~mL}$ acetone and poured into 20 $\mathrm{mL}$ of an ethanol: water phase (1:1 by volume) under magnetic stirring at room temperature. The organic solvents were eliminated under reduced pressure (Büchi R144, Switzerland). The freshly prepared nanoparticles (NP) were incubated with $10 \mathrm{mg}$ ovalbumin in $5 \mathrm{~mL}$ of water for $1 \mathrm{~h}$ at room temperature under magnetic stirring. The resulting carriers were purified by centrifugation at $27,000 \mathrm{x} \mathrm{g}$ for $20 \mathrm{~min}$. The supernatants were removed and the pellets resuspended in water. The purification procedure was repeated twice and finally, the formulations were freeze-dried (Genesis 12EL, Virtis, USA) using sucrose (5\%) as cryoprotector.

2.2.2. Preparation of OVA-encapsulated Gantrez, nanoparticles (NP II, NP III and $N P I V)$ 
Briefly, $5 \mathrm{mg}$ OVA were dispersed in $1 \mathrm{~mL}$ acetone by ultrasonication (Microson $^{\mathrm{TM}}$ ) for 1 min under cooling. The OVA dispersion was then added to $4 \mathrm{~mL}$ acetone containing $100 \mathrm{mg}$ Gantrez and the mixture was stirred for $30 \mathrm{~min}$ at room temperature. Then, the polymer was desolvated by the addition of $20 \mathrm{~mL}$ ethanol: water phase (1:1 by volume). The organic solvents were eliminated under reduced pressure (Büchi R-144, Switzerland). Some batches were cross-linked by incubation with either $5 \mu \mathrm{g}$ or $10 \mu \mathrm{g}$ 1,3-diaminopropane/mg copolymer (NP III and NP IV, respectively) for 5 minutes under magnetic stirring at room temperature. Non cross-linked (NP II) and cross-linked nanoparticles (NP III and NP IV) were purified by centrifugation and lyophilised as described above.

\subsection{Characterisation of Gantrez nanoparticles}

The particle size and the zeta potential of nanoparticles were determined by photon correlation spectroscopy (PCS) and electrophoretic laser doppler anemometry, respectively, using a Zetamaster analyser system (Malvern Instruments, UK). The samples were diluted with distilled water and measured at room temperature with a scattering angle of $90^{\circ}$. All measurements were performed in triplicate.

The morphological characteristics of the nanoparticles were obtained by scanning electron microscopy (LEO Electron Microscopy Inc, Thornwood, NY) operating at $3 \mathrm{kV}$ with a filament current of about $0.5 \mathrm{~mA}$. Prior to observation, the nanoparticles were coated with a platinum laker of about $2 \mathrm{~nm}$ using a Cressington sputter-coated $208 \mathrm{HR}$ with a rotatory-planetary-tilt stage, equipped with a MTM-20 thickness controller. 
The yield of the nanoparticles preparation process was determined by gravimetry from freeze-dried samples as described previously ${ }^{16}$.

The quantification of the amount of associated ovalbumin to nanoparticles was determined using the microbichinchoninic acid (Micro BCA) protein assay. For this purpose, the nanoparticulate pellet, obtained after centrifugation, was digested with $\mathrm{NaOH} 0.1 \mathrm{~N}$ for 24 hours at $4^{\circ} \mathrm{C}$. Then, the resulting solutions were analysed in a spectrophotometer at $570 \mathrm{~nm}$. Calibration curves from 1 to $100 \mu \mathrm{g} / \mathrm{mL}$ of OVA $\left(r^{2}>0.999\right)$ were performed using a control ovalbumin solution in $\mathrm{NaOH} 0.1 \mathrm{~N}$. Each sample was assayed in triplicate and results were expressed as the amount of ovalbumin (in $\mu \mathrm{g}$ ) per $\mathrm{mg}$ nanoparticles. Similarly, the encapsulation efficiency (E.E.) was estimated as follows:

$$
\text { E.E. }(\%)=\left(Q_{\text {associated }} / Q_{\text {initial }}\right) \times 100 \quad[\text { Eq. 1] }
$$

where $\mathrm{Q}_{\text {initial }}$ is the initial amount of ovalbumin added per $\mathrm{mg}$ of polymer that form the NP and $\mathrm{Q}_{\text {associated }}$ is the amount of encapsulated OVA per mg of NP.

\subsection{In vitro release study of ovalbumin from nanoparticles}

OVA-loaded nanoparticles $(8 \mathrm{mg}$ ) were dispersed in eppendorf tubes by vortexing in $1 \mathrm{~mL}$ phosphate buffer saline (PBS, pH 7.4). Release study was conducted at $37 \pm 1^{\circ} \mathrm{C}$ under rotating agitation during 7 days. At defined times, the sample tubes were centrifuged at 26,500 x $g$ for $20 \mathrm{~min}$ and the protein content was determined in the supernatants by micro-BCA assay and performed in a 96-well multiscaner autoreader (Labsystems iEMS Reader MF). Empty nanoparticles were used as control and 
subjected to the same procedure. Release profiles were expressed in terms of cumulative release, and plotted versus time.

\subsection{Immunisation studies}

Animal protocols were performed in compliance with the regulations of the Ethical committee of the University of Navarra in line with the European legislation on animal experiments (86/609/EU).

BALB/c mice, females of 8 weeks old (supplied by Harlan Interfauna Ibérica, Spain), were randomized into seven groups of 5 mice. Animals were intradermally immunised with $10 \mu \mathrm{g}$ OVA incorporated in one of the following formulations: i) OVAcoated nanoparticles (NP I); ii) OVA encapsulated in conventional nanoparticles (NP II); iii) OVA encapsulated in cross-linked nanoparticles with $5 \mu \mathrm{g} \mathrm{DP} / \mathrm{mg}$ (NP III); iv) OVA encapsulated in cross-linked nanoparticles with $10 \mu \mathrm{g}$ DP/mg (NP IV); v) OVA adsorbed in alhydrogel (OVA-Alum); vi) free OVA dissolved in sterile buffered saline solution; and, vii) empty Gantrez nanoparticles (NP).

Blood samples from the the retroorbital plexus were collected on days $0,7,14$, 28 and 35 post-immunization. The samples were centrifuged ( $3000 \mathrm{x} \mathrm{g}, 10 \mathrm{~min})$ and the resulting sera were pooled. Finally, each pool was diluted 1:10 in PBS and stored at $80^{\circ} \mathrm{C}$ until analysis.

\subsection{Quantification of anti-OVA antibodies in serum}

Specific antibodies against OVA $\left(\operatorname{IgG}_{1}\right.$ and $\left.\operatorname{IgG}_{2 \mathrm{a}}\right)$ were determined in the pooled sera by indirect ELISA. Briefly, microtiter wells (cliniplatte EB, Labsystems, Finland) 
were coated with $1 \mu \mathrm{g}$ OVA in $100 \mu \mathrm{L}$ sodium carbonate-bicarbonate buffer $(0.05 \mathrm{M}$; $\mathrm{pH}$ 9.6) at $4^{\circ} \mathrm{C}$ for $15 \mathrm{~h}$. The plates were washed with PBS-Tween $20(1 \%)$ and serum samples were added in two-fold serial dilutions in PBS-Tween $20(1 \%)$ starting with 1:40, and incubated at $37^{\circ} \mathrm{C}$ for $4 \mathrm{~h}$. After washing again with PBS-Tween 20 (1\%), the plates were incubated, at $37^{\circ} \mathrm{C}$ for $2 \mathrm{~h}$, with anti-mouse $\operatorname{IgG}_{1}$ or $\operatorname{IgG}_{2 a}$ peroxidase conjugates diluted 1:1000 in PBS-Tween 20 (1\%). The plates were washed and, finally, incubated with the substrate chromogen solution $\left(\mathrm{H}_{2} \mathrm{O}_{2}\right.$-ABTS). The optical density (OD) was determined at $\lambda_{\max } 405 \mathrm{~nm}$ (iEMS Reader MF de Labsystems, Finlandia). Measurements were performed by triplicate and data were expressed as the reciprocal of a serum dilution whose optical density was 0.2 above blank samples.

\subsection{Evaluation of complement activation by 2-D immunoelectrophoresis of C3}

The complement activation in the presence of different nanoparticles was evaluated by quantification of the conversion of $\mathrm{C} 3$ into $\mathrm{C} 3 \mathrm{~b}$ by 2-D immunoelectrophoresis using a polyclonal antibody to human $\mathrm{C} 3$. This technique was performed by a modification of a protocol previously described by Labarre et al ${ }^{18}$. Briefly, human serum was obtained after calcifying plasma from healthy donors and stored at $-80^{\circ} \mathrm{C}$ until use. The electrophoresis buffer contained $63 \mathrm{mmol} / \mathrm{L}$ Tris, 27 $\mathrm{mmol} / \mathrm{L}$ tricine, $1 \mathrm{mmol} / \mathrm{L}$ calcium lactate and $3 \mathrm{mmol} / \mathrm{L}$ sodium azide $(\mathrm{pH} 8.6)$ as described before by Nanjee et al ${ }^{19}$. Veronal buffer saline (VBS) containing $0.15 \mathrm{mM}$ $\mathrm{Ca}^{2+}$ and $0.5 \mathrm{mM} \mathrm{Mg}^{2+}$ ions $\left(\mathrm{VBS}^{2+}\right)$ and VBS containing $40 \mathrm{mM}$ ethylenediamine tetra-acetic acid (VBS-EDTA) were prepared as described previously ${ }^{20}$. For the experiment, $100 \mu \mathrm{L}$ of an aqueous dispersion of nanoparticles (containing a surface area of nanoparticles of $10 \mathrm{~cm}^{2}$ ) were incubated under gentle agitation for $1 \mathrm{~h}$ at $37^{\circ} \mathrm{C}$ with 50 
$\mu \mathrm{L}$ human serum and $50 \mu \mathrm{LVBS}^{2+}$. The relative surface of nanoparticles was calculated from the average hydrodynamic diameters according to Vittaz et $\mathrm{al}^{21}$. After incubation, it was performed the first electrophoresis $(600 \mathrm{~V}, 16 \mathrm{~mA}, 90 \mathrm{~min})$ on $1 \%$ agarose gel and the second-dimension elecrophoresis $(500 \mathrm{~V}, 12 \mathrm{~mA}, 18 \mathrm{~h})$ on Gelbond ${ }^{\circledR}$ films in agarose gel plates which contained a polyclonal antibody to human C3 (anti C3 and C3b goat antiserum, Sigma, France). As a negative control it was used Human serum diluted in VBS-EDTA (1/4 v/v) and as a positive control Dex-An nanoparticles (Dextran nanoparticles made by anionic polimerization) incubated in serum diluted in $\mathrm{VBS}^{2+}$. In order to analyze the spontaneous complement activation without any activators we used another control with serum diluted in $\mathrm{VBS}^{2+}$. Gels were stained with Coomassie Blue (Sigma, France) and peaks height recorded. The results of the complement activation were expressed as a percentage of $\mathrm{C} 3 \mathrm{~b}$ detected on the plate regarding the sum of the peaks height of $\mathrm{C} 3$ and $\mathrm{C} 3 \mathrm{~b}$.

\subsection{Statistical analysis}

The physico-chemical characteristics were compared using the Student t-Test. $P$ values $<0.05$ were considered significant. For the evaluation of the complement activation, statistical comparisons were performed using the one-way analysis of variance test (ANOVA) and Tukey HSD test. $P<0.01$ was considered as a statistically significant difference. All calculations were performed using $\operatorname{SPSS}^{\circledR}$ statistical software program $\left(\operatorname{SPSS}^{\circledR} 10\right.$, Microsoft, USA).

\section{Results}




\subsection{Characterisation of Gantrez nanoparticles}

The main physico-chemical characteristics of Gantrez formulations are summarised in Table 1. The size of OVA-loaded nanoparticles was significantly higher than for empty nanoparticles $(\mathrm{NP})(\mathrm{p}<0.05)$. Thus, OVA-coated nanoparticles were found to be 2-times higher than empty nanoparticles. Besides, the size of OVAencapsulated nanoparticles slightly increased with increasing amounts of cross-linking agent - e.g. from 205 (NP II) to $270 \mathrm{~nm}$ when using $10 \mu \mathrm{g}$ DP/mg (NP IV). Their morphological characterization by SEM showed homogeneous populations of sphericalshaped particles with lower size than that obtained by photon correlation spectroscopy (Fig. 1). The coating of nanoparticles with OVA (NP I) or the use of the cross-linking agent (NP III and NP IV) significantly increased the negative charge of conventional nanoparticles $(\mathrm{p}<0.05)$.

Concerning the OVA content, it is interesting to note that, under our experimental conditions, the coating of nanoparticles enabled us to load 2-times more protein that the encapsulation process (i.e 68 vs $36 \mu \mathrm{g} / \mathrm{mg}$ ). Furthermore, the crosslinkage process of nanoparticles (NP III and NP IV) also negatively affected the protein content and reductions of about $20 \%$ in the OVA entrapment were observed, comparing with NP II. Similarly, with increasing the DP concentration the nanoparticle yield decreased.

\section{Table 1}

\section{Figure 1}

Figure 2 shows the in vitro release of OVA from nanoparticle formulations in PBS buffer. For OVA-coated nanoparticles, the protein release profile was characterised by a latency period of at least 6 hours, in which less than $5 \%$ of the loaded protein was 
released, followed by a pulse of release of about $40 \%$ of the OVA content. On the contrary, OVA-encapsulated nanoparticles (NP-II, NP-III and NP-IV) displayed a profile characterised by a burst effect of about $10-20 \%$ of the loaded protein followed by a sustained period of slow release. Furthermore, cross-linkage with increasing amounts of DP reduce the release rate of OVA.

\section{Figure 2}

\subsection{Antibody response in $B A L B / c$ mice}

Figure 3 shows the anti-OVA $\operatorname{IgG}_{1}$ and $\mathrm{IgG}_{2 \mathrm{a}}$ titres (Th2 and Th1 markers, respectively) in sera after intradermal immunisation with the different formulations.

Concerning Th2 markers, all OVA-loaded nanoparticles (NP I, NP II, NP III and NP IV) displayed higher $\mathrm{IgG}_{1}$ titres than the OVA-Alum group. In addition, all nanoparticle formulations appear to induce a similar profile of antibodies secretion, which was also different to that observe for the control group. This profile was characterised by a short lag-time, of about 1 week, followed by a rapid an intense period of anti-OVA $\operatorname{IgG}_{1}$ secretion and, 14 days post-immunisation, a final and longer step of "plateau" of the antibody levels. At the end of the experiment (day 35), the highest $\mathrm{IgG}_{1}$ titres were found for NP III and NP IV. In fact, cross-linked nanoparticles induced the production of 2-times higher levels of antibodies than NP II or 3-times higher than OVA-coated nanoparticles.

Furthermore, Gantrez nanoparticles were able to induce significative Th1 responses, characterized by the $\mathrm{IgG}_{2 \mathrm{a}}$ isotype, however some differences were observed among them. Thus, for NP II and NP III, the lag-time was of at least 7 days, whereas for NP I and NP IV, this perod was of at least 14 days. On the other hand, 35 days post- 
immunization, NP I and NP II, appeared to reach a plateau, whereas NP III and NP IV were still increasing their antibody levels. On day 35 , NP II displayed a $\operatorname{IgG}_{2 a}$ titer which was found to be 2-times higher than for NP II and 5-times higher than for NP I.

\section{Figure 3}

\subsection{Activation of $C 3$ in the presence of the nanoparticles}

Figure 4 shows the percentage of $\mathrm{C} 3 \mathrm{~b}$ (activated $\mathrm{C} 3$ ) as an indicator of the complement activation induced by the nanoparticles after incubation in human serum containing divalent ions.

VBS-EDTA and serum incubated with divalent ions $\left(\mathrm{VBS}^{2+}\right)$ were used as negative controls. All Gantrez nanoparticles were found to have a higher ability to activate the complement comparing with nanoparticles reported previously to be good activators (Dex-An nanoparticles, described previously as strong activators, were incubated with a surface of $1000 \mathrm{~cm}^{2} 18$ whereas in the present study they were incubated at $10 \mathrm{~cm}^{2}$ ). Nevertheless, under the experimental conditions described here, no significant differences between the different formulations tested (NP, NP I, NP II and NP IV) were found $(\mathrm{p}<0.001)$.

\section{Figure 4}

\section{Discussion}

Vaccination and immunotherapy are basic priorities for human and animal health, and a large number of adjuvants are therefore under investigation. Basically, polymeric adjuvant delivery-systems are able to get a prolonged antigen exposure by 
facilitating the antigen uptake by the immune system cells. As a consequence, the delivery of encapsulated antigens results in more efficient immune activation than the equivalent amounts of free antigens ${ }^{22-24}$. Here, we describe the use of a novel vectoradjuvant based on nanoparticles of the polymer Gantrez, which is biocompatible and has been proposed as drug carrier for pharmaceutical applications ${ }^{16,25}$. The use of this copolymer led us to increase dramatically the immunogenicity of a soluble protein like OVA used here as an antigen model. In fact, this is the first description on literature of the use of Gantrez polymer for adjuvant purposes.

The choice of an adjuvant depends on the kind of immune response required to treat pathogenic infections and immunological disorders. On the other hand, the sort of the immune response generated depends on the intracellular fate of the antigen. Thus, exogenous antigens may lead towards a $\mathrm{T}$ lymphocyte-MHC II restricted antigen presentation; in contrast, antigens delivered intracellularly tend to elicit a MHC I restricted presentation. Another critical preliminar consideration concerns the main branches of the immune response based on the different Th subsets activation. Th1 cells release predominantly IL-2 and gamma interferon (IFN- $\gamma$ ) in response to the antigenic stimulus, activating the named "cellular" immune response. In contrast, Th2 cells release predominantly IL-4 and IL-5, inducing the "humoral" immune response. In practical means, the generation of a predominantly Th1 response is associated with resistance to intracellular pathogens and allergic processes. The response after Th2 activation is, by contrast, more appropriated for the effective control of extracellular pathogens and autoimmune diseases. Accordingly, in order to induce a different presentation to the immune system cells, and hence, to study the elicited immune response, formulations containing OVA protein either coating the surface or included into nanoparticles of Gantrez were prepared. 
First of all, OVA loading percentage data demonstrated the efficiency of the method of preparation used here to get a different physical distribution of that antigen within the particle (OVA coating or encapsulation). All the nanoparticles displayed a similar and homogeneous size (See Table 1 and Figure 1), being slightly higher for NP I (nanoparticles with OVA coating the surface) than for OVA-encapulated formulations (NP II, NP III and NP IV) (See Table 1). The scanning electron microscopy of freezeddried formulations showed that the size of the nanoparticles was slightly lower than the one measured by photon correlation spectroscopy, what could be due to the swelling of the particles in aqueous media forming a "sponge" structure. This fact has been previously described for legumin nanoparticles by Mirshahi et al ${ }^{26}$. On the other hand, as it was expected, the outer coating with OVA (NP I) rendered more electronegative particles with respect the ones that were formulated with OVA encapsulated. This fact demonstrated that in NP I, the OVA coated the nanoparticle surface. The zeta potential was also more negative as long as the amount of cross-linking agent increased.

Although OVA loading on NP I formulation was higher than OVA encapsulation in the other formulations (NP II, NP III and NP IV), the encapsulation efficiency was almost the same for all formulations. The yield of the process was also similar for the different nanoparticles, being approximately $80 \%$ as described previously by Arbos ${ }^{16}$.

The in vitro release studies, demonstrated that, as expected, the OVA release from NP I formulation (OVA coating the surface) was faster than from NP II, NP III and NP IV (OVA encapsulated) ${ }^{27,28}$.

This fact can be easily related to the immune response. In this context, we observed that the elicited immune response after NP I administration was of lower 
intensity than for the other formulations (See Figure 3). Thus, we can estimate that most of the elicited antibody response by NP I was due to the OVA released just after the inoculation. These results suggest that both physical distribution of OVA and the consequent controlled release of the antigen exert an effect in the immunostimulating capacity of the nanoparticles.

On the other hand, cross-linkage with increasing amounts of DP slightly diminished the OVA in vitro release from the nanoparticles. Concerning in vivo results, some differences were found. For IgG1 titres, cross-linked nanoparticles slightly increased the antibody levels. On the contrary, IgG2a titres increased more rapidly for NP II (non cross-linked nanoparticles) and NP III (cross-linked with $5 \mu \mathrm{g} \mathrm{DP} / \mathrm{mg}$ ) than for NP IV (cross-linked with $10 \mu \mathrm{g} \mathrm{DP} / \mathrm{mg}$ ). In fact, for this last formulation, no presence of this antibody isotype was observed before 2 weeks post-administration. In addition, 5 weeks post-administration, the levels of antibodies of the animals immunized with NP III continued to increase whereas for NP II, the levels of antibodies reached a plateau. All of these results may suggest than an optimal cross-linking concentration is required.

Sustained presentation of antigen by these systems could be the decisive factor in inducing long lasting immune responses. Maximizing a desired response by controlling delivery pathways is crucial in vaccine development and immunotherapy. It has long been suggested that the sustained release characteristics of the antigen delivery system, related to the "depot effect" contribute to the immunogenicity-enhancing effect of adjuvant by producing a prolonged immunological response ${ }^{23,29}$. However, in this case, Th2 would be expected to predominate in response to a free-released OVA. On the contrary, our data on a selective Th1 response suggest that the associated antigenGantrez-nanoparticles, particularly those cross-linked with DP, is more important than a 
depot effect. The potent, long-lasting immune responses induced after a single injection of antigen-loaded NP III may be due to its efficient uptake by dendritic cells (DCs), efficient antigen processing and sustained presentation to T-helper cells. However, the use of Gantrez copolymer, diaminopropane as cross-linking agent and physical location of the antigen may contribute to its presentation to APCs (antigen presenting cells).

The complement activation data demonstrated that Gantrez nanoparticles can strongly activate the cleavage of $\mathrm{C} 3$ into $\mathrm{C} 3 \mathrm{~b}$. This fact was corroborated comparing Gantrez particles with Dex-An nanoparticles, used as positive control. These nanoparticles were described previously as strong activators when incubated with a surface of $1000 \mathrm{~cm}^{2}$ but their capacity to activate complement was considerably reduced for the such low surface area used in the present work $\left(10 \mathrm{~cm}^{2}\right)^{18}$. As well known, complement activation induces phagocytosis by macrophages ${ }^{30}$, thus, this strong activation of Gantrez nanoparticles could enhance the particle uptake by APCs. But the direct or indirect roles in the activation of APCs and induction of Th1/Th2 mediated immunity remain to be determined.

Finally, as a conclusion of this work, it can be remarked that Gantrez AN nanoparticles seemed to be a strong adjuvant. In this context, the titres elicited by intradermal administration of $10 \mu \mathrm{g}$ of OVA in combination with the new nanoparticleadjuvant were found to exceed titers induced by immunization with the same amount of antigen. Furthermore, the induced titers were elicited with a relatively smaller amount of antigen used by other autors ${ }^{31-33}$, supporting the potential feasibility of our system. Further benefits of this new antigen delivery system are currently being studied in vaccination and immunotherapy in animal models.

\section{Acknowledgements}


This research was supported by "Gobierno de La Rioja", "Fundación Universitaria de Navarra", ISP Corp., and grant from the "Ministerio de Ciencia y Tecnología" (SAF2001-0690-C03; AGL2004-07088-C03-02/GAN) in Spain. Authors want also to thank Audrey Valette (UPR CNRS 2801, Thiais) and Madeleine Besnard (UMR CNRS 8612) for their help in the characterisation of nanoparticles by microscopy. 


\section{References}

1. D. Sesardic and R. Dobbelaer, Vaccine 22, 2452 (2004).

2. E. B. Lindblad, Vaccine 22, 3658 (2004).

3. L. Leserman, J Liposome Res 14, 175 (2004).

4. L. Bungener, J. Idema, W. ter Veer, A. Huckriede, T. Daemen and J. Wilschut, J Liposome Res 12, 155 (2002).

5. N. Westerfeld and R. Zurbriggen, J Pept Sci 11, 707 (2005).

6. A. Huckriede, L. Bungener, T. Stegmann, T. Daemen, J. Medema, A. M. Palache and J. Wilschut, Vaccine 23 Suppl 1, S26 (2005).

7. B. Morein, K. F. Hu and I. Abusugra, Adv Drug Deliv Rev 56, 1367 (2004).

8. R. L. Garcea and L. Gissmann, Curr Opin Biotechnol 15, 513 (2004).

9. R. Noad and P. Roy, Trends Microbiol 11, 438 (2003).

10. W. Jiang, R. K. Gupta, M. C. Deshpande and S. P. Schwendeman, Adv Drug Deliv Rev 57, 391 (2005).

11. P. Couvreur and F. Puisieux, Advanced Drug Delivery Reviews 10, 141 (1993).

12. D. T. O'Hagan and R. Rappuoli, Pharm Res 21,1519 (2004).

13. M. Singh and D. T. O'Hagan, Pharm Res 19, 715 (2002).

14. M. van Zijverden and B. Granum, Toxicology 152, 69 (2000).

15. J. G. Archambault and J. L. Brash, Colloids Surf B Biointerfaces 39, 9 (2004).

16. P. Arbos, M. A. Arangoa, M. A. Campanero and J. M. Irache, Int J Pharm 242, 129 (2002).

17. H. H. Salman, C. Gamazo, M. A. Campanero and J. M. Irache, J Control Release 106, 1 (2005).

18. D. Labarre, C. Vauthier, C. Chauvierre, B. Petri, R. Muller and M. M. Chehimi, Biomaterials 26, $5075(2005)$.

19. M. N. Nanjee, C. J. Cooke, W. L. Olszewski and N. E. Miller, Arterioscler Thromb Vasc Biol 20, $2148(2000)$.

20. M. D. Kazatchkine, D. Fearon, J. Silbert and K. Austen, J Exp Med 150, 1202 (1979).

21. M. Vittaz, D. Bazile, G. Spenlehauer, T. Verrecchia, M. Veillard, F. Puisieux and D. Labarre, Biomaterials 17, 1575 (1996).

22. M. Murillo, M. M. Goni, J. M. Irache, M. A. Arangoa, J. M. Blasco and C. Gamazo, J Control Release 85, 237 (2002). 
23. D. T. O'Hagan, H. Jeffery, K. J. Maloy, A. M. Mowat, D. Rahman and S. J. Challacombe, Adv Exp Med Biol 371B, 1463 (1995).

24. P. M. Munoz, M. Estevan, C. M. Marin, M. Jesus De Miguel, M. Jesus Grillo, M. Barberan, J. M. Irache, J. M. Blasco and C. Gamazo, Vaccine (2005).

25. S. A. Mortada, M. A. el Egaky, A. M. Motawi and K. A. el Khodery, J Microencapsul 5, 311 (1988).

26. T. Mirshahi, J. M. Irache, J. Gueguen and A. M. Orecchioni, Drug Development and Industrial Pharmacy 22, 841 (1996).

27. M. Amidi, S. G. Romeijn, G. Borchard, H. E. Junginger, W. E. Hennink and W. Jiskoot, J Control Release (2005).

28. Y. Xu, Y. Du, R. Huang and L. Gao, Biomaterials 24, 5015 (2003).

29. M. Singh and D. T. O'Hagan, Int J Parasitol 33, 469 (2003).

30. M. C. Carroll and M. B. Fischer, Current Opinion in Immunology 9, 64 (1997).

31. N. Puri, E. H. Weyand, S. M. Abdel-Rahman and P. J. Sinko, Vaccine 18, 2600 (2000).

32. N. L. Bennewitz and J. E. Babensee, Biomaterials 26, 2991 (2005).

33. M. M. Matzelle and J. E. Babensee, Biomaterials 25, 295 (2004). 
Development of a novel vaccine delivery system based on Gantrez nanoparticles

Sara Gómez, Carlos Gamazo, Beatriz San Roman, Christine Vauthier, Marta Ferrer, Juan M. Irache

Table 1. Physico-chemical characteristics of Gantrez nanoparticles.

Data were represented by mean $\pm \operatorname{SD}(n=10)$.

\begin{tabular}{|c|c|c|c|c|c|}
\hline & Size $(\mathbf{n m})$ & $\begin{array}{c}\text { Zeta } \\
\text { Potential } \\
(\mathrm{mV})\end{array}$ & $\begin{array}{c}\text { OVA } \\
\text { content } \\
(\mu \mathbf{g} / \mathbf{m g})\end{array}$ & $\begin{array}{c}\text { Encapsulation } \\
\text { efficiency (\%) }\end{array}$ & Yield (\%) \\
\hline NP & $158 \pm 3$ & $-45.1 \pm 0.5$ & - & - & $85.3 \pm 0.8$ \\
\hline NP I & $300 \pm 4$ & $-61.3 \pm 3.8$ & $67.8 \pm 20.2$ & $47.5 \pm 2.1$ & $87.2 \pm 0.6$ \\
\hline NP II & $205 \pm 1$ & $-41.4 \pm 2.5$ & $36.1 \pm 3.8$ & $50.5 \pm 5.3$ & $83.9 \pm 0.8$ \\
\hline NP III & $239 \pm 4$ & $-50.8 \pm 2.9$ & $30.1 \pm 4.5$ & $42.1 \pm 6.3$ & $78.2 \pm 1.1$ \\
\hline NP IV & $270 \pm 2$ & $-57.5 \pm 3.1$ & $31.4 \pm 4.2$ & $44.1 \pm 5.9$ & $74.9 \pm 0.2$ \\
\hline
\end{tabular}

NP: empty nanoparticles; NP I: OVA-coated nanoparticles; NP II: OVA encapsulated in nanoparticles; NP III: OVA encapsulated in cross-linked nanoparticles with $5 \mu \mathrm{g}$ DP/mg; NP IV: OVA encapsulated in cross-linked nanoparticles with $10 \mu \mathrm{g} \mathrm{DP} / \mathrm{mg}$. 
Development of a novel vaccine delivery system based on Gantrez nanoparticles

Sara Gómez, Carlos Gamazo, Beatriz San Roman, Christine Vauthier, Marta Ferrer, Juan M. Irache

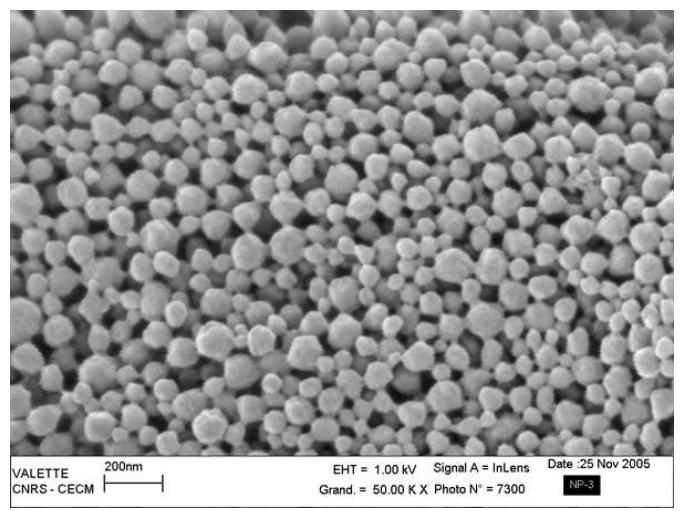

Figure 1. Scanning electron microscopy photograph of NP III (OVA encapsulated in cross-linked nanoparticles with $5 \mu \mathrm{g} \mathrm{DP} / \mathrm{mg}$ ). 
Development of a novel vaccine delivery system based on Gantrez nanoparticles

Sara Gómez, Carlos Gamazo, Beatriz San Roman, Christine Vauthier, Marta Ferrer, Juan M. Irache

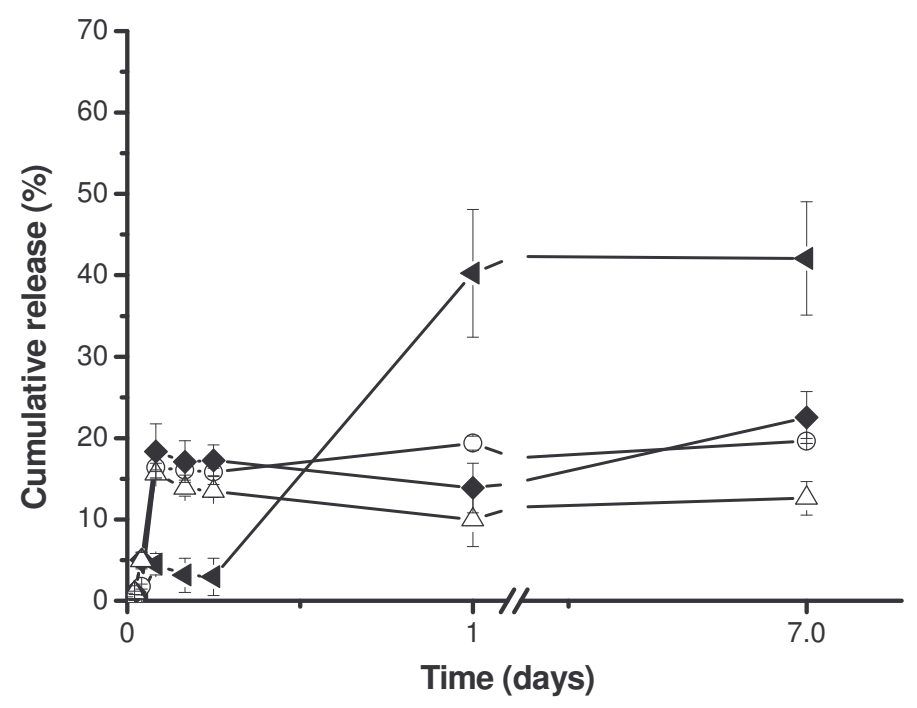

Figure 2. In vitro release of OVA from Gantrez formulations in PBS. NP I (४): OVA-coated nanoparticles; NP II (०): OVA encapsulated in nanoparticles; NP III ( $\bullet$ : OVA encapsulated in cross-linked nanoparticles with $5 \mu \mathrm{g}$ DP/mg; NP IV $(\Delta)$ : OVA encapsulated in cross-linked nanoparticles with $10 \mu \mathrm{g} \mathrm{DP} / \mathrm{mg}$. Data express the mean of the cumulative amount of OVA released vs. time (mean \pm $\mathrm{SD}, \mathrm{n}=3)$. 


\section{Development of a novel vaccine delivery system based on Gantrez}

\section{nanoparticles}

Sara Gómez, Carlos Gamazo, Beatriz San Roman, Christine Vauthier, Marta Ferrer, Juan M. Irache
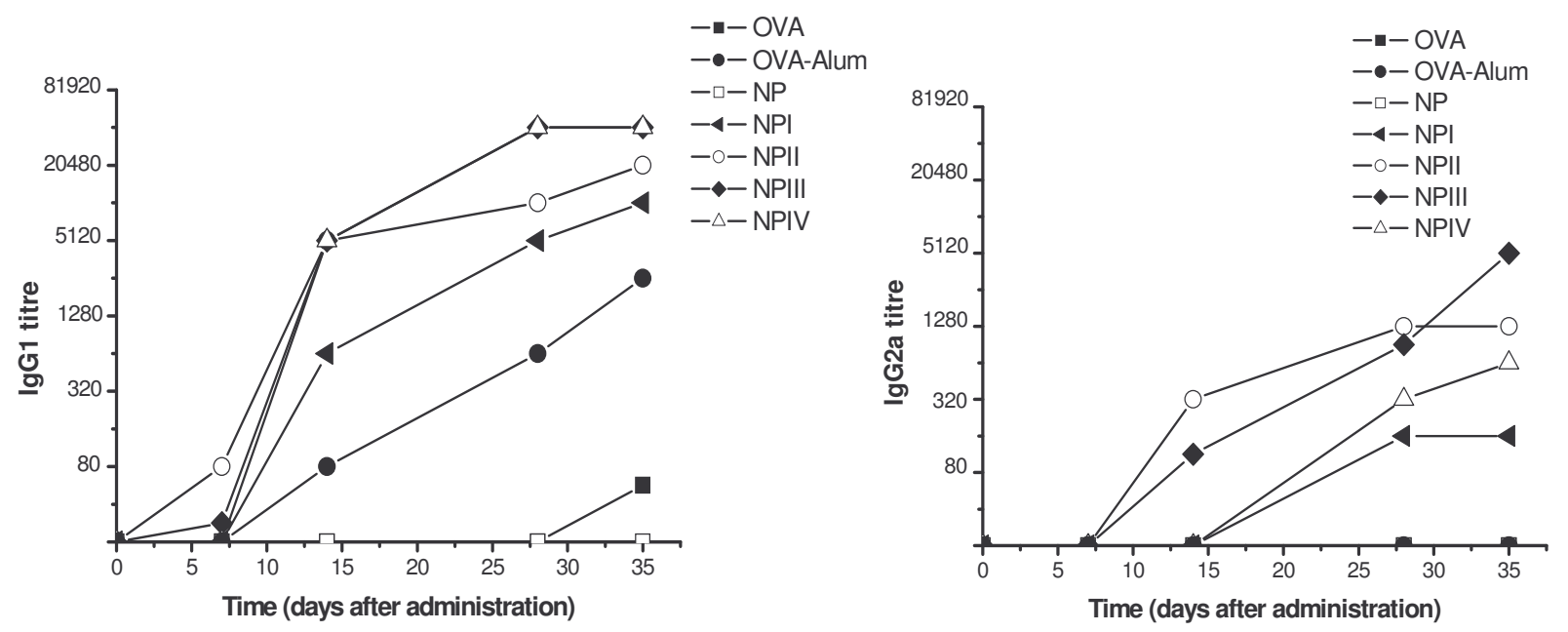

Figure 3. Anti-OVA $\lg _{1}$ and $\lg _{2 a}$ titres in sera after intradermal immunisation with: ovalbumin solution (OVA) (a), ovalbumin adsorbed in alhydrogel (OVA-Alum) (•), blank nanoparticles (NP) (口), ovalbumin coated nanoparticles (NP I) (४), ovalbumin encapsulated nanoparticles (NP II) (०) and cross-linked ovalbumin encapsulated nanoparticles (NP III ( $\bullet$ ) and NP IV $(\Delta)$ ). The antibody titre is defined as the reciprocal dilution giving an optical density. Female BALB/c mice were immunised intradermally with $10 \mu \mathrm{g}$ ovalbumin as follows: i) OVA in solution; ii) OVA adsorbed in alhydrogel (OVA-Alum); iii) OVA coated nanoparticles (NP I); iv-vi) 
OVA encapsulated in nanoparticles (NP II), and nanoparticles crosslinked with DP (NP III and NP IV); and vii) empty nanoparticles (NP). (OD) reading at $405 \mathrm{~nm}$ of $\geq 0.2$. 
Development of a novel vaccine delivery system based on Gantrez nanoparticles

Sara Gómez, Carlos Gamazo, Beatriz San Roman, Christine Vauthier, Marta Ferrer, Juan M. Irache

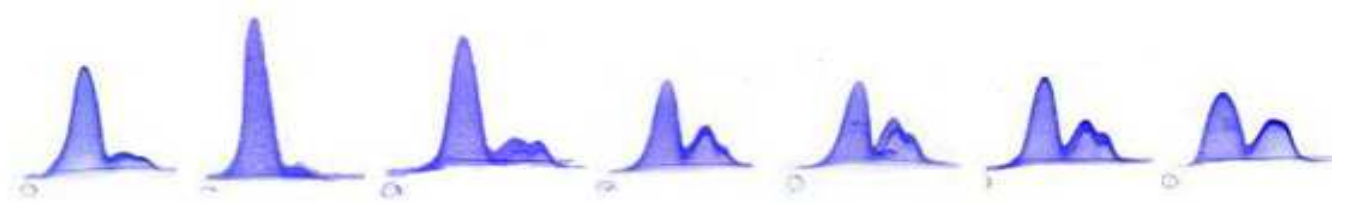

\begin{tabular}{|c|c|c|c|c|c|c|c|}
\hline & $\begin{array}{c}\text { Serum } \\
\text { VBS-EDTA }\end{array}$ & $\begin{array}{c}\text { Serum } \\
\text { VBS }^{2+}\end{array}$ & Dex-An & NP & NP I & NP II & NP III \\
\hline$\%$ C3b & $6.2 \pm 2$ & $12.7 \pm 0.4$ & $14.5 \pm 4.7$ & $31.1 \pm 1.4$ & $34.1 \pm 1.1$ & $32.5 \pm 0.1$ & $35.8 \pm 2$ \\
\hline
\end{tabular}

Figure 4. Percentage of $\mathrm{C} 3$ activated (\% C3b) measured by 2-D immunoelectrophoresis after 60 min incubation of $10 \mathrm{~cm}^{2}$ of samples with $50 \mu \mathrm{L}$ of human serum at $37^{\circ} \mathrm{C}$. The relative amounts of $\mathrm{C} 3$ and C3b are indicated by the first and second peak respectively. The samples were as the following: Serum VBS-EDTA (negative control), Serum $\mathrm{VBS}^{2+}$ (experimental conditions), Dex-An (nanoparticles previously reported as strong complement activators by Labarre et $\mathrm{al}^{18}$ ), and Gantrez AN nanoparticles (NP, NP I, NP II and NP III). (mean $\pm \mathrm{SD}, \mathrm{n}=3$ ). ${ }^{* * *} \mathrm{p}<0.001$ for Gantrez AN nanoparticles vs Dex-An. 